\title{
NEDERLANDSCH-ROTTINEESCHE SAMENSPRAKEN
}

\author{
UITGEGEVEN DOOR
}

H. KERN.

Van de samenspraken, die onder de Sawuneesche bijdragen in $\mathbf{D}$. XLI, p. 190-196 van dit tijdschrift zijn opgenomen, bestaat ook eene Rottineesche bewerking, welke hierachter wordt medegedeeld. Wie die vertaling vervaardigd heeft, is onbekend, maar zonder twijfel was het een inlandsch onderwijzer, die het Hollandsch goed machtig was. Trouwens uit onderscheiden brieven die ondergeteekende van Rottineesche onderwijzers af en toe ontvangen heeft, blijkt dat menigeen onder hen niet alleen onberispelijk, maar zelfs sierlijk Nederlandsch weet te schrijven.

Van dezelfde hand als de Nederlandsch-Rottineesche samenspraken is de Nederlandsch-Rottineesche woordenlijst, die hier mede den lezer wordt aangeboden.

Het dialect waarvan zich de schrijver in beide stukken bedient, is met geringe verschillen 1 hetzelfde als dat hetwelk ten grondslag heeft gestrekt aan de door Niemann uitgegeven spraakkunst van Fanggidaej in deze Bijdragen XLI, p. 554 vgg., en aan de woordenlijst van Pello 2 in Bijdr. XXXIX, 1 vgg., alsook in de spraakkunstige schets van Manafe in Bijdr. XXXVIII, p. 636 vgg. Naar hetgeen Niemann l.c. mededeelt, vertegenwoordigt het dialect door Fanggidaej gebezigd den tongval van Termanu; vergelijkt men wat Manafe over de dialectische verschillen op Rotti zegt, dan komt men tot de slotsom dat men in Termanu, Keka en Talae nagenoeg hetzelfde en in Baä en Lòle een slechts weinig afwijkend dialect spreekt. Aangaande de overige tongvallen zijn wij te gebrekkig ingelicht dan dat wij nu reeds zouden kunnen beproeven, den graad van

${ }^{1}$ Bijv. kampa, buffel, bij Fanggidaej en Pello kapa; ai, wij, elders $a m i$; $e i$, gijlieden, elders $\mathbf{e m i}$.

Z Zóo is de ware naam van den Rottineeschen onderwijzer. 
verwantschap waarin ze onderling tot elkaar staan, eenigermate te bepalen. Voorloopig zou men de Rottineesche tongvallen in twee groepen kunnen verdeelen: dezulke die de klanken $r$ en $l$ bezitten, en de andere die alleen de $l$ hebben. Tot de eerste groep behooren, volgens de gegevens bij Manafe, de tougvallen van Upao, Ringgou, Landu, Ti, Unale en Dela; tot de tweede de overige. Ten opzichte van 't behoud der $k$ aan 't begin van een woord of tusschen twee klinkers, bijv. in kò, 2 ps. enk., këmi, 2 ps. mv.; ikaq, visch, staat de taal van de gewesten Upao, Ringgou, Landu, Bilba, Diu, Lelenuk, Bokai op een ander standpunt dan de rest, doch met uitzondering van de drie eerstgenoemde hebben deze tevens eene jongere $l$ voor $r$, bijv. in lala, paard, Jav. djaran. Vooralsnog schijnt het al- of niet voorkomen der $r$ het beste shibboleth ter onderscheiding der groepen te wezen. De algemeene type der taal is op geheel Rotti dezelfde, zoodat de bewoners van verschillende deelen des eilands malkander zonder moeite verstaan, gelijk Manafe uitdrukkelijk verzekert.

In zake van spelling wijkt de onbekende, aan wien wij de $\mathrm{N}$. R. samenspraken en woordenlijst te danken hebben in kleinigheden af van de door Manafe, Pello en Fanggidaej gevolgde. De aanwijzing der uitspraak geschiedt bij hem op de volgende wijze:

v [kort] als in dăg, lěg, ligg, kŏp, mŭg.

- [lang] als in dāgen, lēven, Kō, pēren, mūur.

$\cap[$ stom $]$ als in tempĕren.

Deze opgave lijdt, zooals ieder terstond opmerken moet, aan licht verklaarbare, en daardoor gemakkelijk te verbeteren gebreken. Vergelijkt men wat Fanggidaej over de uitspraak mededeelt en wat Niemann l.c. daarbij aanteekent, dan kan men de bedoeling van den schrijver wel nagaan en zich eene ten naastenbij juiste voorstelling der uitspraak maken. Met zijne lange $a$ bedoelt hij eenen klank overeenkomende met onze $a$ in open lettergrepen, en men zal als regel kunnen stellen dat in 't Rottineesch elke $a$ in eene opene, geaccentueerde lettergreep klinkt als de onze in het overeenkomstige geval. Daarentegen klinkt de $a$ in elke niet geaccentueerde lettergreep kort; nu eens wordt dit door Manafe en onzen schrijver aangeduid door de schrijfwijze $a h$, dan weêr laten zij de $h$ weg. Het teeken $\cap \mathrm{kan}$, ondanks de opgave, geen stomme letter aanduiden, want van een stomme $a, o, u$ kan geen sprake zijn, en toch vinden wij in 't handschrift van den anonymus telkens die klinkers zoo van dat kapje voorzien. Zelfs boven eene $e$ beteekent het kapje 
niets anders dan wat Fanggidaej, Pello en Manafe met het kortheidsteeken te kennen geven, namelijk eene zeer korte é fermé. Overal nu, waar ik in het handschrift het omgekeerde kapje vond, heb ik het vervangen door het teeken van de Pěpĕt, hoewel dit in 't Rottineesch, het zij hier nogmaals gezegd, niet de waarde van onze zgn: stomme $e$ en de Jav. $\check{e}$ heeft. Etymologisch zal men in gevallen waar 't Javaansch een Pĕpĕtklank heeft, in 't Rottineesch nu eens eenvoudig $e$, dan weêr hierachter, gelijk bij Fanggidaej en Manafe, $\check{e}$ ontmoeten. In 't eerste geval rust de klemtoon op den klinker, in het tweede niet; dus telu, drie, met klemtoon op de $e$, uitgesproken als de Fransche é fermé, ofschoon men in 't Javaansch zegt tělu. Zoo ook beli = O.-Jav. wěli, Mal. běli; maar hědis, ziekte, etymologisch $=$ Jav. pěděs, Dajaksch peres 1 . Het kortheidsteeken hetzij boven eene $e$ of een anderen klinker duidt aan, dat de klemtoon valt op de onmiddellịk volgende lettergreep, waarmede de kortheid of wel de verkorting van de vorige gepaard gaat.

Overal waar de anonymus het kortheidsteeken gebruikt, heb ik het vervangen door den accent grave, want het is uit alles duidelijk dat de man bedoeld heeft den klank der Fransche $e$ ouvert uit te drukken. Het door hem gekozen voorbeeld leg is niet geheel juist, hij had moeten nemen gebed, doch hoe zou hij het onderscheid tusschen de twee soorten van $\grave{e}$, bijv. in gebed en bed gekeud hebben, daar hem zeker geen zijner Hollandsche onderwijzers daarop ooit opmerkzaam heeft gemaakt? In gesloten lettergrepen heb ik het teeken van de gravis weggelaten, daar volgens onze spelling de uitspraak van zelf gegeven is.

Hier en daar heb ik, misschien noodeloos, om de spelling van den schrijver niet geheel op zijde te zetten, diens sluitende $a h$ weêrgegeven met $a^{\prime}$, nl. in lupia' ${ }^{2}$. In bolih, kunnen, heb ik de $h$ behouden, omdat het woord eigenlijk in 't geheel geen Rottineesch, maar Maleisch is. Het woordje $t a$, niet, heb ik in navolging van het handschrift, nu eens $t \bar{a}$, dan weêr $t a$ geschreven. Naar den aard van het Rottineesche klankstelsel heeft het woordje natuurlijk een gerekte $a$, wanneer het met klemtoon wordt uitgesproken, en een korte in het tegenovergestelde geval. Of en wanneer de ontkenuing

1 Pello spelt hédis, e. vgl. Zijdelings wordt het hier beweerde dat de Rottineesche $\breve{e}$ als eene é fermé luidt, bevestigd door 't feit dat het hedendaagsche Ròtě ontstaan is uit ouder Ròti.

1 Daarentegen is sioh, negen, van het hs. steeds vervangen door sio, waarin de $\partial$ aan onze scherpkorte $o$ beantwoordt; vgl. Niemann, 1. c. p. 555. Pello spelt sia, waarin de $\stackrel{a}{a}$ een gerekten $\grave{o}$-klank vertegenwoordigt, gelijk bijv. in 't Jav. hanå.

5e Volgr. VIII. 
ooit in 't laatste geval verkeert, blijkt uit de stukken niet. Over 't algeıneen is zooveel duidelijk dat het lengteteeken vaak geheel overbodig is en ook dat de samensteller niet altijd met zich zelven: noch met de andere autoriteiten overeenstemt. Zoo schrijft hị låò, lăo, reizen, terwijl Pello en Fanggidaej láå hebben. Wie van hen goed gehoord heeft, kan hier natuurlijk niet uitgemaakt worden. Het is volstrekt niet onmogelijk, dat de accentuatie in 't gebruik niet geheel vast is.

Ten opzichte van de woordenlijst valt op te merken, dat de samensteller er van de werkwoorden, die in de Nederlandsche kolom steeds in infinitiefvorm staan, op drieërlei wijze vertolkt. Nu eens geeft hij in 't Rottineesch den naakten stam, dan weêr den 3 ps. enk., gekenmerkt door 't voornaamwoordelijk voorvoegsel $n a, n$ '; eindelijk den stam voorafgegaan door $t a, t$. Voorbeelden van de eerste categorie zijn: lao, reizen; hai, afzetten; tao, doen; van de tweede: natudul, aantoonen; naselu antwoorden; van de derde: takamuti, lasteren; tamanako, stelen; tisa, dooden. In de gedrukte lijst zijn de werkwoorden der tweede soort zóó opgegeven als in 't handschrift; alleen heb ik dan in de Nederlandsche kolom er aan toegevoegd de aanduiding: 3 ps. enk. Daarentegen heb ik de $t a, t$ overal weggelaten en vervangen door een streep, omdat het voorgevoegde $t a, t$ alleen licht tot verwarring aanleiding kan geven. Bepalen wij ons tot de zooeven aangevoerde voorbeelden: kamuti, niet takamuti, is de stam. en wel een secundaire stam, bestaande uit muti en het prefix $k a$, een korteren vorm van maka, en gelijkwaardig met het in zooveel verwante talen voorkomende maka, aka, resp. paka. Vandaar dat het nomen actoris luidt manamakamuti, lasteraar '; zoo ook van den stam isa, 3 ps. enk. nisa, n. act. manisa, dooder. Het werkw. stelen luidt in 't Rottineesch manako en nako, 't eerste geheel identisch met het Dayaksche manakau, het tweede met een korter gelijkwaardig prefix, ons wel bekend uit het Makassaarsch, Bugineesch, Javaansch, enz. De 3 ps. enk. is namanako. Wat kan nu den anonymus bewogen hebben de werkwoorden op drieërlei wijze te be-

1) Ten onrechte houdt Fanggidaej (Bijdr. l. c. p. 566) mana voor een prefix. Mana vóór medeklinkers, doch man vóór klinkers, bestaat uit het verouderde vragend en relatief vnw. $m a$ (vgl. Sumbasch), wie, en den 3 ps. enk. van 't werkwoord. Dus van namakamuti, (hij, zij) lastert, komt ma-namakamuti, wie lastert; van nisa, (hij, zij) doodt, stam isa: ma-nisa, wie doodt.

1) Volgens de theorie van Fanggidaej is in $n a$, enz. het prefix $a$ - vervat. Dit is mogelijk, doch dan moet in nisa, hij doodt; neu, hij gaat heen, e. dgl. de $a$ vóór de beginletter uitgevallen zijn. 
handelen? Gaan wij te rade met het opstel van Manafe, dan zien wij dat ook deze drie soorten van werkwoorden onderscheidt: veranderlijke, onveranderlijke en dezulke die een hulpwoord vereischen. Die van de tweede soort geeft hij in stamvorm, de overige kenmerkt hịj door een voorgevoegd $t a, t$. Het stelsel van den samensteller der woordenlijst komt in zooverre hiermede overeen, dat ook hij de onveranderlijke werkwoorden, d.i. dezulke die geen voornaamwoordelijken exponent aannemen, in stamvorm geeft, maar op welken grondslag zijne indeeling der twee overige categoriën, die bịj Manafe beide $t a, t$ vertoonen, berust, is niet recht duidelijk. Het schijnt dat zijne bedoeling geweest is alle veranderlijke intransitieven door $t a$ aan te duiden.

Tot de eigenaardigheden van onzen schrijver - of van zijnen tongval - behoort het veelvuldig gehruik van $m p$, waar Pello en Fanggidaej $p$ schrịjven, bijjv. mpeda voor peda; kampa voor kapa; ook soms ngg voor $g$, als in nggasa, gans, bij Pello gansa. In dit opzicht sluit hij zich aan bij de uitspraak van Manafe. Op zich zelf beschouwd zou deze eigenaardigheid ons niet het recht geven te beslniten dat 's mans tongval een andere is dan het Termanusch men denke aan 't Javaansch - maar beschouwt men de zaak in verband met de opgaven van Manafe, dan komt men tot de gevolgtrekking dat èn Manafe èn de maker van de woordenlijst meer de uitspraak van Baä en Lòle, dan die van Termanu volgen. Intusschen is er geen scherpe grens. Manafe geeft vormen als ai en ami, ei en emi naast elkander, en in de woordenlijst worden sampi en sapi door elkaar gebruikt. Even inconsequent is onze schrijver in de onderscheiding van $n g$ en $n g g$.

Om de bruikbaarheid der lijst te verhoogen, heb ik ette!ijke woorden er aan toegevoegd, ontleend aan Pello, Fanggidaej en Manafe, met wier initialen men die toevoegsels gemerkt zal vinden. 


\section{NEDERLANDSCH-ROTTINEESCHE SAMENSPRAKEN.}

Waar zijt ge gisteren avond Afika' lèodaèna ò mèmè bè? geweest?

Ik ben te huis gebleven om mijne vischnetten te herstellen.

Au kăda uma akahia au dā-

Gij hebt vergeten bij N. N. een bezoek te brengen.

Neen, ik heb dat niet vergeten en heb N. N. dan ook meegedeeld dat ik te huis moest blijven.

Is uw zoontje nog altijd ziek?

$\mathrm{Ja}$, de jongen heeft nog altijd koorts.

Gaat uw dochtertje naar school?

$\mathrm{Ja}$, sedert Januari van dit jaar.

Gaat ge nu mede naar de pasar?

$\mathrm{Ja}$, als ge wat op mij wilt wachten tot ik mijne netten en gereedschap geborgen heb.

Laat die zaken daar maar liggen, niemand komt toch daaraan.

Als ik die laat liggen, dan gaan de kinderen daarmede spelen en dan raken ze weg.

Haast $\mathrm{u}$ dan, want het is reeds negen uur.

Ik zal spoedig gereed zijn.

Hebt ge geld bij u ?

Niet veel, mijn vrouw is met den sleutel van mijn kast reeds vroeg vitgegaan. langga.

O mafandèlè henin mu titinò N. N.

Tā, au tā afandèlè henin, dè au fè leu lafada N. N. āé au mesti kăda uma.

Ana manè-ma bei namahĕdi?

Hei, kakanaka bei namahĕdi seku-seku.

Ana feò-ma neu sŏda sò?

Hei, nèmè bula Januari teuk ia,

Ò lèo pasaka mu beki ia bòe?

Hei, tè nāu fbòe na mahāni au dei, fò ela au apěda heni au dālangga ma au bua lŏanggala dei.

Ela buas sila lèmè ndia, esa tā neu taò sala bòe.

Makanenima ela sala lèmè ndia na kakanakāla hăi la sala fò lakaminak fò mompò sala.

Lai-lai fā dei, tè liu siò sò.

Au bāsa lai-lai ndia sò.

Ò muni doik bòe?

Tā nŏuka, saongga neni au alamalingga ngòena, dè ana lăò sò. 
Goeden morgen, hebt ge goed geslapen?

Dank u, vrij wel.

Hebt ge reeds ontbeten?

$\mathrm{Ja}_{\mathrm{a}}$, maar het eten smaakt mij niet, ik ben wat onwel.

Laten wij dan een wandeling maken, dit zal $\mathbf{u}$ goed doen.

Ik wil wel, maar ik ben bang dat wij spoedig regen zullen krijgen

Als ge dat denkt, dan zullen wij onze wandeling tot heden namiddag vitstellen.

Ik geloof dat het beter is.

Wilt ge een kop koffie gebruiken?

Gaarne, maar geef mij eerst een glas drinkwater.

Komt ge morgen bij mij 't middagmaal gebruiken?

Gaarne, maar ik kan dan niet lang blijven, want ik krijg gasten; zij komen uit het gebergte.

Zijn ze ook bekenden van mij?

Ik geloof wel dat gij die menschen kent.

Dan zal ik u naar huis brengen, om uwe gasten te ontmoeten.
Fatāi malòlè, ò sunggu nò malòlè?

Malòlè neu ò, malòlě-ā bòe.

Ò mŭa minu sò?

Hei, tè au amĕda nanăa nininuk tā malăda, au aongga hi hědisa.

Mai teu kŏkòk, fô ela mamĕda aòmu malòlè.

Au nau bòe, tè au bi ita hampu ŭda lai-lai.

Makanenima ò maè lèo ndia na ela nòsòkia dei fikò teu kǒkok.

$\mathrm{Au}$ amĕda malòlè lemak lè̀̀ ndia.

Ò nau minu kòfi mangkò esa?

Malòlè, tè fè makahuluk au òe nininuk glas esa dei.

Fŏa mai (mpilak) ò mai mŭa minu lědohanana nai au ia?

Malòlè, tè an t⿳亠 ⿵冂 bolih ala doka, fuila lèò au umangga leu; lèmè lètèk lain mai.

$\mathrm{Au}$ hataholi nalelang sila?

Amĕdakā ò malelak hataholi sila bòe.

Dei fò au onggo lèò uma teu, fô ela matonggò mò fui sila.
Ik hoor dat gij een paard gekocht hebt.

$\mathrm{Ja}$, een merrie met een hengstveulen.

Hoeveel hebt gij voor die dieren betaald?

$\mathrm{Zij}_{\mathrm{ij}}$ kosten veertig gulden, maar de verkooper heeft mij toegestaan die som langzamerhand te betalen in djagong, gierst, uien en padie.
$\mathrm{Au}$ amanènè ò asa mala ndala esa sò.

Hei, ndala ina esa nò anana manè-anak.

Ò tifa bău bè nèu bana sila?

Belinala lupia' ha-hulu, tè manamasěòka nau au tifa fāfā fè mpelak, bètek, laisona ma hădè. 
Dan hebt ge voor de dieren niet te veel betaald.

Neen, dat meende ik ook.

Ik heb verleden week twee karbouwen gekocht, een mannetje en een wijfje, mooie jonge dieren, maar 'ik moest den prijs, zestig gulden, dadelijk betalen.

Waarom dat?

De eigenaar moest op den volgenden dag per stoomschip vertrekken.

Ik zal trachten ou zooveel geld bij elkaar te krijgen, dat ik in dit jaar nog een hengst zal kunnen koopen.

Ik zal voor $u$ een mooien hengst koopen, dan zullen wij een stoeterij oprichten en de veulens die geboren worden onder elkaar verdeelen.

Dat wil ik wel. Koop dan maar spoedig dien hengst.
Lè̀ ndia sò na, ò tā tifa nŏuka neu bana sila.

Tā, amědaka lèò ndia.

Mamasò makahuluka au asa ala kampa dua, manè-anak esa ma ompu-anak esa, bana mulik mesan, tè au tifa belinala lupia' nè-hulu nò lai-laik.

$\mathrm{Hu}$ hata?

Maenaka misti lăò fòa mai kia săè ofa-hăika.

Au sangga adudulu doik defu ndia, fò ela teuk ia au asa ala ndala manè esa.

Au sangga fè ò ndala manè malòlè esa, fò ita taò heheluk esa, bonggi ndala ana bău bè na tabăè.

Au nau lè̀ ndia. Asa lailaik ndala manè ndia.
Wat zie ik, gaat gij een huis bouwen?

$\mathrm{Ja}_{\mathrm{a}}$, want het oude staat op invallen.

Dat zal $\mathrm{u}$ weêr veel geld kosten en ge hebt reeds zooveel moeten uitgeven voor het huwelijk van uw zoon met de dochter van den goudsmid.

Dat is werkelijk zoo, maar ik heb zelf alle materialen voor dit huis verzameld, en de vader van mijnn schoondochter zal mij rotang en atap geven.
Maè dò au ita hata ndia, ò tad uma esa?

Hei, uma uluka sangga tŭu sò.

Ò mahani maheni doik nòuka bali, ma ò maheni nòuka sò bòe neu ana-manè-ma sasaòna nò manataò lilòa ana-feò-na.

Těbè lèò ndia, tè au mesang ngau tati basa-basa di-ai-ala taò neu uma ia, tè au fètò feungga amana fè au uè ma sinik. 
Ik zal u van tijd tot tijd komen helpen.

Doe dat, want ik vrees, alleen werkende, niet vóór 't vallen der regens gereed te zullen zijn.

Van waar hebt ge dat mooie hout en die groote bamboezen gehaald?

Het hout uit een bosch nabij A. en de bamboe van B.

Dan hebt gij toch veel voor transportkosten moeten uitgeven.

Neen, ik heb van de bamboe een vlot gemaakt en daarop de balken over zee naar hier vervoerd.
Au -dei mai faling gò lăi esa bòe.

Taò lèò ndia, tè au bi fò ela uda bei ta mai tè basan sò.

Tati mala āi malòlè ndia ma ò' matua sila lèmè bè?

$\mathrm{Ai}$-a nèmè nula esa ta dōka nò $\mathrm{A}$. ma ò' nèmè $\mathrm{B}$.

Amĕdaka ò maheni nò-uka neu lěa dò lŭa sala-mai.

Tā, au hăi ala ó'la dè lăi ala lòa-anak esa, fua balokala leu lain de leni sala tungga tasi lai lèò ia māi.
Gaat ge op reis? ik zie dat ge uw prauw gereed makt.

$\mathrm{Ja}$, ik ga naar A. om mijn geiten, kippen en eenden te verkoopen.

Doe mij dan 't genoegen en neem van mij twee varkens mee.

Wat moet ik met die dieren doen?

$\mathrm{Ik}$ moet den Chinees T. te A. twaalf gulden betalen. Verkoop die varkens, betaal met het geld den Chinees en koop voor het overschietende een sarong, twee kapmessen (parangs) en een bijl voor mij.

Gaarne wil ik mij met uwe bestelling belasten.

Wie gaan met $\mathbf{u}$ mee?

Mijn oom, mijn neef en twee zonen $\operatorname{van} \mathrm{K}$.
Ò sangga lăò? Maè dò au ita ò taò sadia ofama.

Hei, au lèò A. u, fò asěò bïaek, manu ma bělè ngala.

Hi bòena muni au bafing dua.

$\mathrm{U}$ taò hata ò bana sila?

Au misti tifa Sinasiu T. manai A. Iupia' sanahulu dua. Masě̀ bafi sila, tifa doikala leu Sinasiu ma buluka doi lenak, asa muni fề au sidi esa, felas dua ma tatala esa.

Au hi taò tungga ò heheluma.

Sè la' lò ò?

Amangga, anangga ma K. ana manè dua. 
Neemt ge de zonen van K. Mò K. ana-manen sila bòe? mede? die jongens zijn zoo wild. kakanak sila bòbòden nala seli.

$\mathrm{Zij}$ zijn wel wat wild, maar goede

Sila mana bòdèkala bòe těbè, tè zeelieden. $\mathrm{Z}_{\mathrm{ij}}$ weten goed met het zeil om te gaan en kunnen het bij 't roeien lang uithouden,

Wanneer vertrekt ge?

Heden avond, als de landwind doorkomt.

Ik zal $\mathrm{u}$ heden namiddag die beide varkens brengen.

Goed, maar laat die dieren goed binden, anders springen zij misschien in zee. hataholi malelakala lai tasilai. Sila lalelak malòlòlè hŏu uli ma ala sèfè lakatakāk lala dokā.

Fai hïda ò lăò?

Lèò daek ia, makanenima ani daèhenaka nakandò.

Nòsok ia dei fò au uni bafi kaduak sila mai.

Malòlè, tè sădi madenu hènggè lahèlè bana sila dua ala bòkè tasi dalè leu.

Jongens, houdt den schoot van

Ei, hòu lāla tali isikònala 't zeil in de hand, want wij krijgen veel wind.

Ik heb den schoot in de hand, maar houdt het roer goed vast.

$\mathrm{P}$, gij moet goed toezien, want de maan is door wolken verduisterd.

Ik zie een prauw rechts vooruit.

Houdt dan wat links af.

Wij zijn reeds nabij 't strand, er staat veel branding en in de rivier kunnen wij niet: het is laag water.

Dan moeten wij hier voor anker blijven liggen tot het water wast. Laat het anker vallen.

Ik ben nog bezig het zeil vast te binden.

Dan moet $\mathrm{P}$. maar 't anker uitneu limamala, tò ita hampu ani matua.

Au hòu tali isikòka nai au limangga, sădi hòu matalòlòlè ulia.

$\mathrm{P}$., ò mètè matalòlòlè, tè makahatuka kŏasa babā bulaka.

$\mathrm{Au}$ akanaè ofak esa, ndia ita ofana langgana.

Fè ofaka langgana kin fa.

Ita deka to metia, ma lila lampena, tā bolih masuk lèò lè dalè teu: tasia mădak.

Lèò ndia sò na, tŭu naka-a' neu nafu tèmè ia losa tasia lu mai. Tŭu naka-a neu lèò.

$\mathrm{Au}$ bei hènggè la-a. werpen.

Lèò ndia na $\mathrm{P}$. tŭu naka-a neu. 
Weet gij ook waar ik koperdraad en wit en blauw katoen kan koopen?

Bij den Chinees L., maar hij is duur, gij moet veel afdingen.

Waar woont L.?

In de pasarstraat hier vlak bij. Wilt ge mij zijn huis aanwijzen? Ik ben hier niet bekend.

Ik zal $\mathrm{u}$ daarheen brengen.

Ik heb geiten, kippen en eenden in mijn prauw om die hier te verkoopen.

Hoeveel betaalt men hier voor een geit, een kip en een eend?

Voor een geit kunt ge gemakkelijk zes gulden bekomen. Een kip kost hier dertig cent en een eend vijf-en-zeventig cent.

Baba, ik moet twintig vadem koperdraad hebben en een stuk wit en een stuk blauw katoen.

Dit koperdraad kost vijftien cent per vadem, dit stuk wit katoen negen gulden en dit stuk mooi blauw katoen vijf gulden.

$\mathrm{Ge}$ vraagt te veel. Ik wil u voor alles elf gulden geven en zoo ge daarmede niet tevreden zijt, ga ik bij een ander mijne inkoopen doen.

Neen, ik kan u dat alles niet voor elf gulden geven. Ik zou te veel daarop verliezen; maar ik zal $\mathrm{u}$ alles laten voor veertien gulden.

Goed. Hier is vijftien gulden, geef mij dus een gulden terug.

Hier is alles bij elkaar ingepakt.
Ò dòdòna au asa hampu kafa ma tema fulak nò tema ngèok nai sè-a?

Nai Sinasiu L., tè hu belina nŏ-uka, ò mahanika malòe nŏuka.

L. lèò nai bè?

Dalak lèò pasaka neu nai mata ia.

o hi bòena matŭdu au umana nai bè? au bei ta alelak hehelu nai ia.

Defi au ò' ò lèò èlè mu.

$\mathrm{Au}$ uni biiāek, manu ma běbè nai au ofang lain fô sě̀ nai ia.

Nai ia biiāek esa, manu esa ma bĕbè esa belina bănbè?

Biiāek esa hampu mŭdak lupia’ nè. Manu esa belina sen teluhulu ma běbè esa sen hitu-hulu lima.

Baba, au sangga asa kafa lěa dua-hulu ma tema fulak langgak esa ma tema ngèok langga esa.

Kafa ia belina lěa esa sen sanahulu lima, tema fulak langgak esa lupia' siò, tema ngèo malòlè langgak esa lupia' lima.

ò mòkè belina nŏuk nan nasala. Au hihingga tifa basa sala lupia' sanahulu esa, tè buluka ò ta hi lèò ndia, na au a asa nai hataholi hiak.

Tàa , au ta fè basa sala fò beli kăda lupia' sanahulu esa ndia. Lè̀ ndia, na au lunggi nŏuka: tè au bolih fè basa sala beli lupia' sanahulu ha.

Malòlè. Mala lupia' sanahulu lima iala, fè falik au lupia' esa. Au mpoti basa sala sila ia sò. 
Wissel mij dit guldenstuk in Tukal (seluk) lupia' ia neu doi dubbeltjes.

kasanahuluk.

Ik heb nu geen dubbeltjes, Sakarang ia au doi kasanahuluk maar ik kan u helpen aan kwartjes. ta, tè au bolih tulung ò koal. 
NEDERLANDSCH-ROTTINEESCHE WOORDENLIJST.

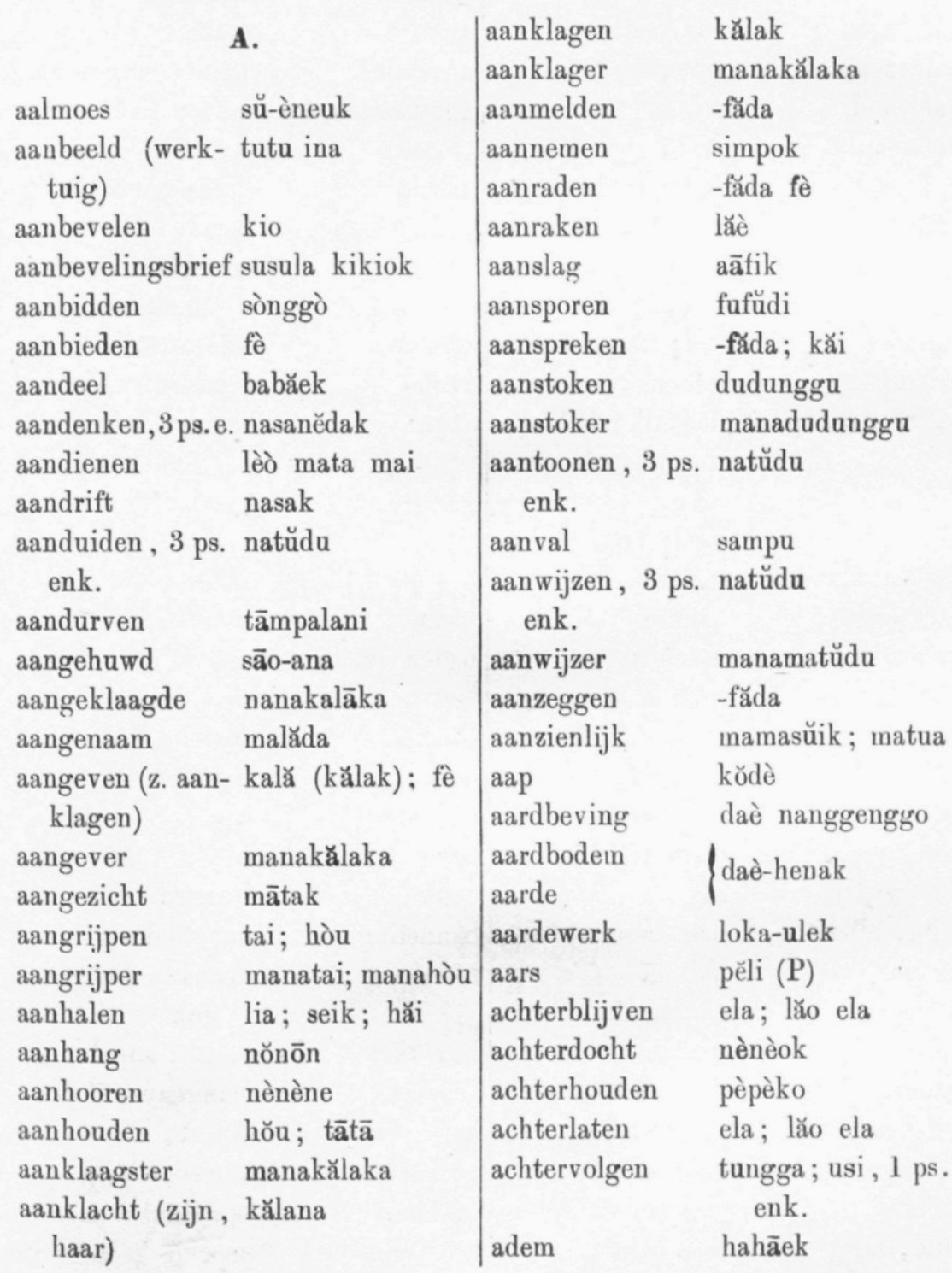




\begin{tabular}{|c|c|c|c|}
\hline ademhaling & hahāèna* & als (indien) & makanaenima \\
\hline afblijven (van & nèmek ; nahani & altijd, altoos & seku-seku \\
\hline iets) 3 ps. enk. & & alvorens & basi bali \\
\hline afbraak & òfề & ambacht & tatāo-nònōik \\
\hline afbranden & putu; kăde & aunbt & tatāos \\
\hline afbreken & $\begin{array}{l}\text { tepa; fanggi; băe; } \\
\text { ketu; lădi; òfề }\end{array}$ & ambtenaar & manahŏu tatāos \\
\hline afdak & lak, lălak & $\begin{array}{l}\text { andermaal } \\
\text { angst }\end{array}$ & bibik \\
\hline afdingen & lòe belin & anker & naka \\
\hline afgezonderd & nanatădak & antwoord & nătak; naselu-na \\
\hline afgrond & felak & antwoorden, $3 \mathrm{ps}$. & năta ; naselu \\
\hline afkeer & ta-hì & enk. & \\
\hline afkomst & bobonggik & arbeid & tatāo-nònōik \\
\hline afloop & tètè-èna & arbeidsloon & ngadi \\
\hline afmaken & $\begin{array}{l}\text { tao-basa; tao-heni; } \\
\text { tati; -isa }\end{array}$ & arm (adj.) & $\begin{array}{l}\text { hatatāk; madò- } \\
\text { dòlek }\end{array}$ \\
\hline afraden & kăi; kena & asthma & hāè susū \\
\hline afsluiting & kekenak & avond & lěodaek \\
\hline afstammeling & $\begin{array}{l}\text { dadădik; bobong- } \\
\text { gik }\end{array}$ & azijn & dosa \\
\hline afstand (de) & dōna & & B. \\
\hline afwenden & hilu; hèò & & \\
\hline afwezen, afwezig & tā-kāna & baadje & bădu \\
\hline afwịjzen & simpek & baard & ngòlòmik \\
\hline afzender & manahaitua & baden (zich) & $\operatorname{diu}(P)$ \\
\hline afzetten & $\begin{array}{l}\text { hăi; sŏu heni; na- } \\
\text { kona; èsè }\end{array}$ & $\begin{array}{l}\text { bak } \\
\text { bakken }\end{array}$ & $\begin{array}{l}\text { mamanak } \\
\text { sesena; hotu }\end{array}$ \\
\hline afzetter & manahăi; manasǒu & balk & balok \\
\hline akelig & manggalāuk & bamboe & ò’ \\
\hline akeligheid (de) & manggalāuka & bang & bi \\
\hline al (reeds) & sò & bank & banggu \\
\hline alle, alles & basa-basa & banneling & nanafuak \\
\hline aldaar & nai nā & bed & mamana susung- \\
\hline algemeen & nakabuak & & guk \\
\hline alhier & nai ia & bedekken & mpoti; mpalu \\
\hline alleen & mesa (kāna) & bedelaar & manggananālok \\
\hline allemaal & basa-basa & bederven & -kalutu \\
\hline allengs & kòè; făfa & bediende & uma-isi \\
\hline allerlei & matamatak & bedienen & -kalalāuk; pakè \\
\hline alle, alles & basa-basa & bedriegen & pèpèkò \\
\hline
\end{tabular}




\begin{tabular}{|c|c|c|c|}
\hline bedrieger & manapèpèkok & beschadigen & -kalutu \\
\hline beëedigen & sò' & beschermen & -samāo; -fadūle \\
\hline & lè-anak & mpen & -kamuti; ā̄li \\
\hline & buneka & ken & \\
\hline (lichaamsd.) & eik & ettelijk & \\
\hline & uik & & \\
\hline eest & bāna & betel (siri) & dăè-dok \\
\hline ginnen & mulai & allen (baren) & bor \\
\hline$n$ & tatoi & & pal \\
\hline & mpă & & dè \\
\hline & nale & & a-isik \\
\hline ren & - făd & & $-\mathbf{n}$ \\
\hline & loi & & \\
\hline den & fua; henuk & & ouk \\
\hline ngrijk & inahi & & a-tāok \\
\hline $\begin{array}{l}\text { eledigen, belas- } \\
\text { teren }\end{array}$ & ti; aāli & $\begin{array}{l}\mathrm{en} \\
\mathrm{k}\end{array}$ & $\begin{array}{l}\text {-ena; P: nu } \\
\text { titono }\end{array}$ \\
\hline eleediger & $\begin{array}{l}\text { manakamuti; ma- } \\
\text { naaāli }\end{array}$ & $\begin{array}{l}\text { bidden } \\
\text { bij (insect) }\end{array}$ & $\begin{array}{l}\text { hul } \\
\text { tan }\end{array}$ \\
\hline beloonen & sĕba & bijl & taka \\
\hline en & helu & bịjna & ela fāka \\
\hline en & suè & $\mathrm{n}$ & $\mathrm{ka}$ \\
\hline leelen & tāo nahenik & len & paӓ $(\mathrm{P})$ \\
\hline ende & lea & blad & dōk (d. i. dåk) \\
\hline men & sŏu & blaffen, 3 ps. enk. & nahou \\
\hline en & -kahuhūk & bla & fulak \\
\hline islagen & kokolak & blauw & ngeok; mamăuk \\
\hline ten & fali & & \\
\hline len & tāo & blijven & -hani \\
\hline $\begin{array}{l}\text { ereiken, } 3 \text { ps. } \\
\text { enk. }\end{array}$ & nalak (P) & $\begin{array}{l}\text { bliksem } \\
\text { blind }\end{array}$ & las \\
\hline erg & lètek & blinde (de) & mpòkèka \\
\hline ergplaats & mamana mpèmpĕ- & bloed & dāk \\
\hline eric & dedĕak & $\begin{array}{l}\text { bloeden, } 3 \text { ps. } \\
\text { enk. }\end{array}$ & \\
\hline en & sæè & bloem & \\
\hline erijder & manasăè & boek (geschrift) & susulak \\
\hline eroep (zijn, h & tatāo (-na) & boezem & \\
\hline$x$ & & & tè ma \\
\hline & & bondgenoot & nōnōk (nŏnōn) \\
\hline
\end{tabular}




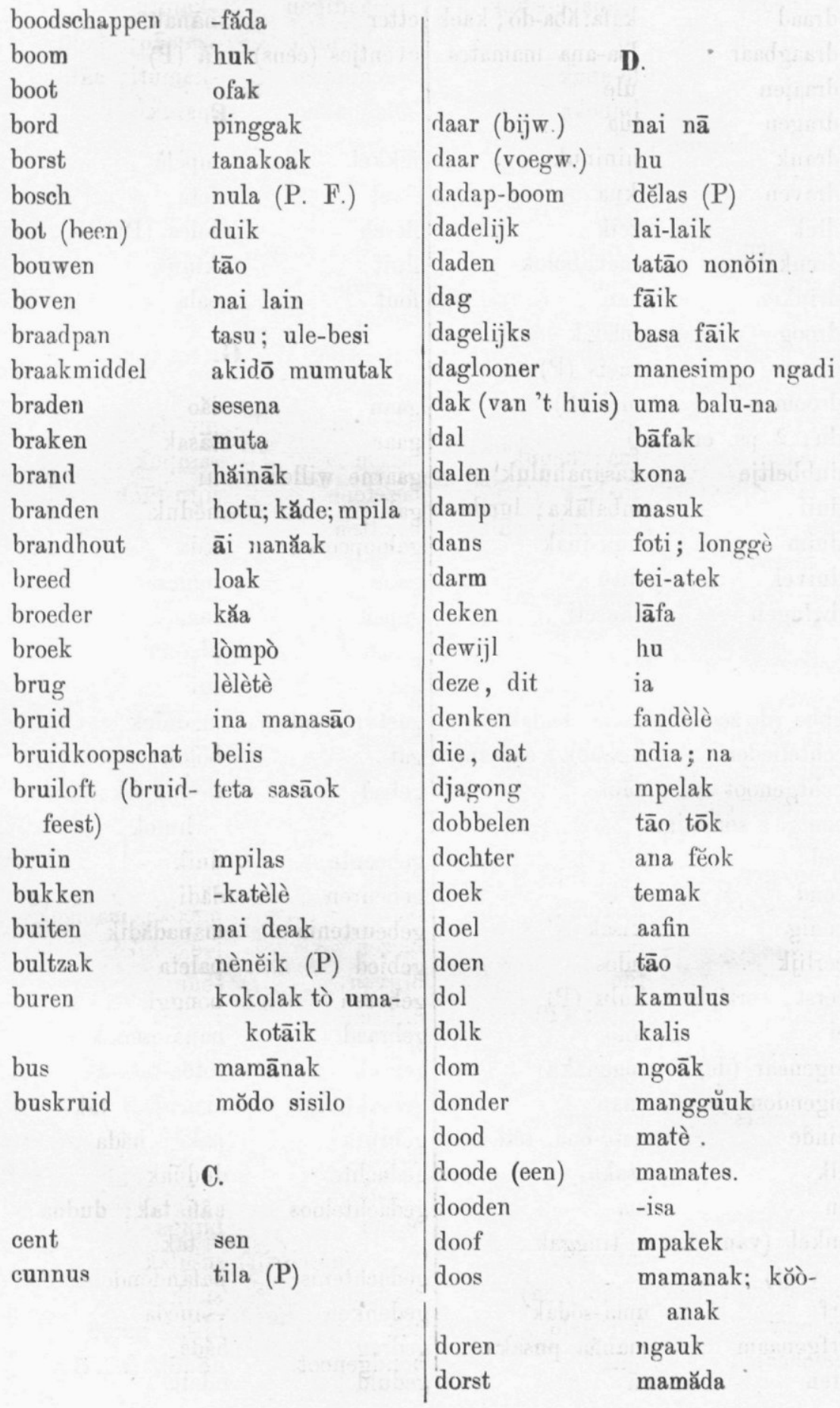




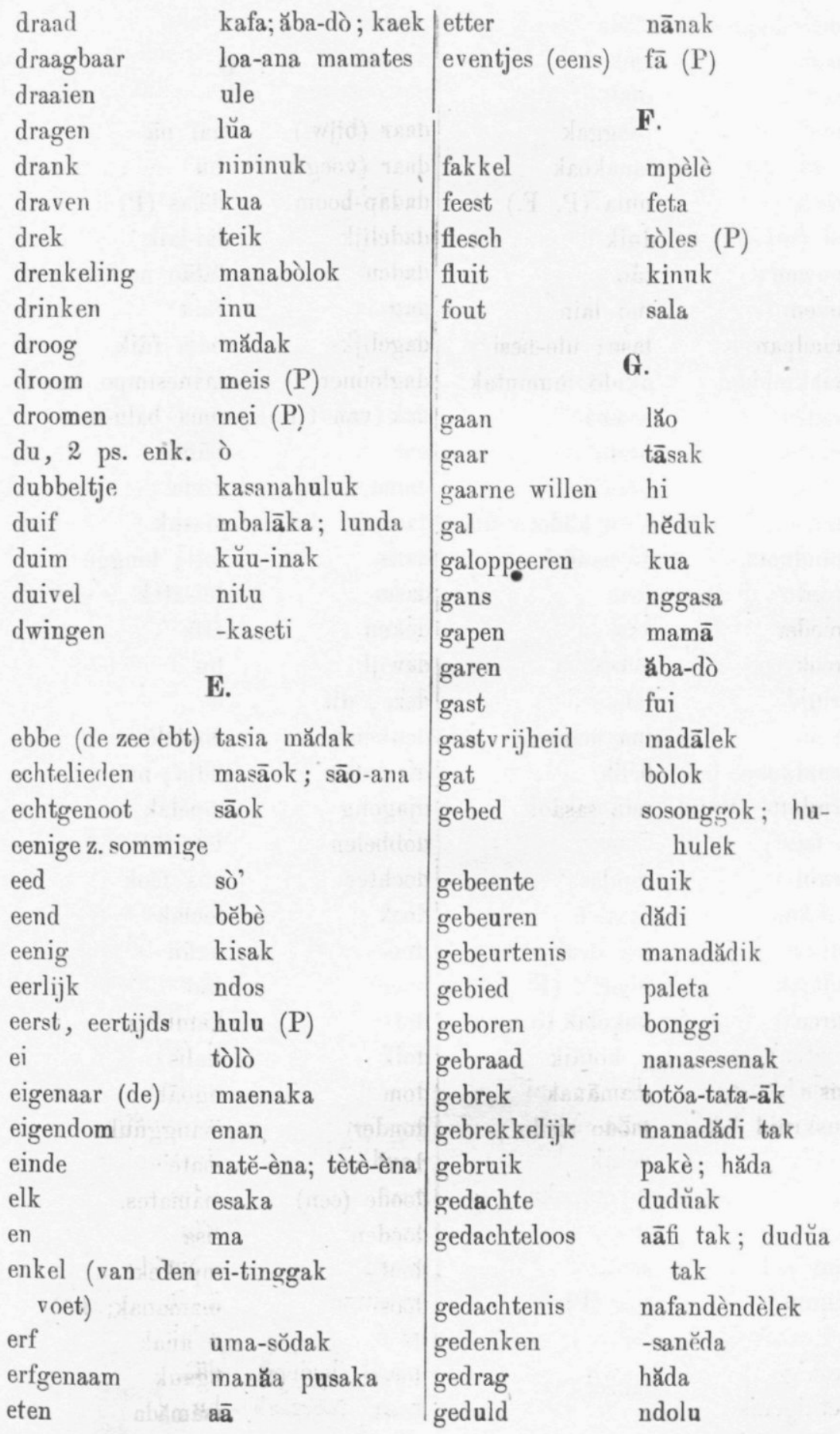




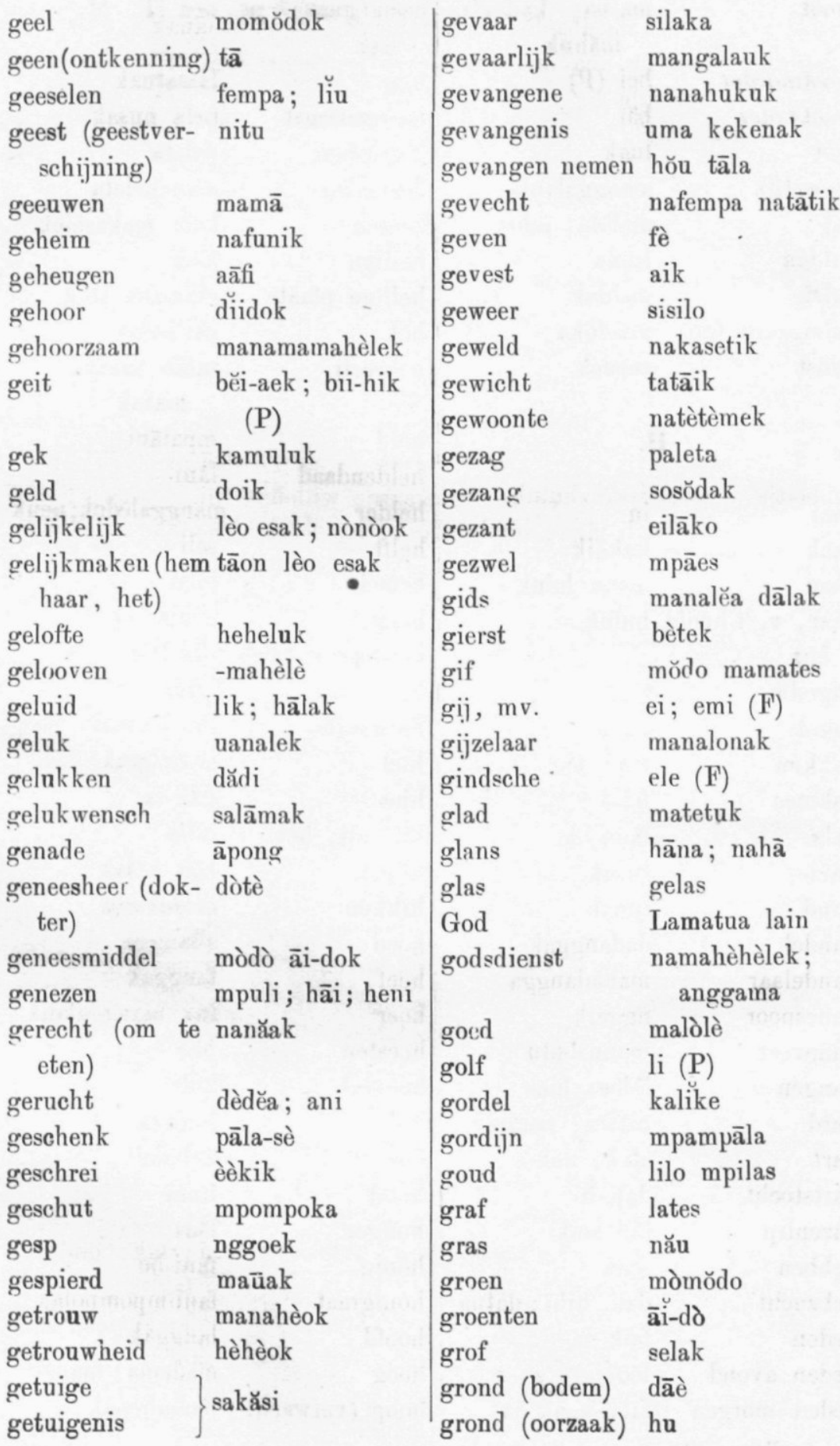




\begin{tabular}{|c|c|c|c|}
\hline groot & $\begin{array}{l}\text { matua; kaděsĕ; } \\
\text { inăhuk }\end{array}$ & $\begin{array}{l}\text { heen (gaan) } 3 \text { ps. } \\
\text { enk. }\end{array}$ & neu (P. M.) \\
\hline grootmoeder & bei $(\mathrm{P})$ & heer & lamatuak \\
\hline grootvader & băi & heerendienst & bela nusak \\
\hline grot & luak & heerschen & paleta \\
\hline gruwelijk & manggalauk & heerscher & manapaleta \\
\hline gul & malolè; ndos & heesch & hala makasèlek \\
\hline gulden & lupia' & heilige & lāok \\
\hline gulzig & madlok & heilige plaats & mamana lāok \\
\hline gulzigaard (de) & maòlòka & hek & osi-bafak \\
\hline gunst & susuek & hekserij & $\begin{array}{l}\text { tatāo nasafali } \\
\text { matak }\end{array}$ \\
\hline & H. & held & mpalāni \\
\hline & & heldendaad & lāni \\
\hline haai & in & helder & manggalědok; neuk \\
\hline haak & kakāik & helft & seli \\
\hline haan & manu laluk & hemel . & lalai \\
\hline $\begin{array}{l}\text { haar, v. 't hoofd } \\
\text { enz. }\end{array}$ & buluk & $\begin{array}{l}\text { hengst } \\
\text { herinneren (zich) }\end{array}$ & $\begin{array}{l}\text { ndala manè } \\
\text {-fandèlè }\end{array}$ \\
\hline hagedis & tèkè & hert & nusa \\
\hline hagel & dadu & herwaarts & lèo ia mai \\
\hline hakken & tāti; lŏd & hiel & ei-tinggak \\
\hline hakmes & felas & hier & nai ia \\
\hline hais & boto-lìk. & hij, zij, het & ndia \\
\hline hamer & tutuk & hïgen & hāè kisak \\
\hline hand & limak & hikken & mesukudu \\
\hline handel & dadanggak & hoed & silangga \\
\hline handelaar & manadangga & hoef & fanggak \\
\hline hanespoor & nggaik & hoer & ina manggalauk \\
\hline haneveer & manu-bulu & hoesten & bŏò \\
\hline hangen & lòlǒe; lona & hoeveel & hida \\
\hline hard & matea; nempek & hok & longga \\
\hline hart & atek; dalek & hol & kabòlok \\
\hline hartstocht & dalè-hi & hond & busa \\
\hline hazenlip & bifi soik & honger & lăas \\
\hline hebben & -ena & honig & fani-òe \\
\hline hebzucht & dalè hihī; dātua & honigraat & fani-mpompolak \\
\hline heden & faik ia & hoofd & langgak \\
\hline heden avond & lěo-daèk ia & hoog & madema ; manalu \\
\hline heden morgen & fafai-anak ia & hoop (verwacht.) & ) namahenak \\
\hline 5e Volgr. VII & & & 7 \\
\hline
\end{tabular}




\begin{tabular}{|c|c|c|c|}
\hline hoop (stapel) & unuk & jongen & tăè anak \\
\hline hooren & -manènè & juist (waar) & tětu (P) \\
\hline hoorn & susulak & \multirow{2}{*}{\multicolumn{2}{|c|}{$\mathbf{K}$. }} \\
\hline hopen & mahena & & \\
\hline lout & $\overline{\mathrm{a}} \mathrm{i}$ & & \\
\hline huid & louk & kaal & mpolik \\
\hline huilen & ki; ngasi & kaap & tăduk \\
\hline huis & uma & kaars & lilik \\
\hline hulp & fafalik & kaart (van een & daè-matak; kar \\
\hline huwelijk & saoana (?) & land) & \\
\hline huwelijksfeest & feta sasaok & kaarten (spelen) & -kaminak susulak \\
\hline huwen & $s^{a_{0}}$ & kakkerlak & hihingi $(\mathrm{P})$ \\
\hline & & kalebas & bonggo \\
\hline & I. & kalf & sapi-ana \\
\hline & & kalk & hă \\
\hline ieder & esaka & kam & sauk \\
\hline iemand & hataholi esa & kameraad & $\mathrm{tia}[\mathrm{k}](\mathrm{P})$ \\
\hline iets & hata & kamp (leger- & \\
\hline ijver & manggatek & plaats) & ofu \\
\hline ijverig & " & kamper & matatik \\
\hline ijverzucht & hi manggatè & kan (subst.) & kan; kas \\
\hline ijzer & besi & kanker & hĕdi dalek \\
\hline k & au & kanon & mpompoka \\
\hline in & nai dalè & kant (zijde) & bifik; tataik \\
\hline indien & makanenima & kantoor & kanto \\
\hline ingaan & lèo dalek tèu & kar & kaleta \\
\hline ingang & lelesu & karbouw & kampa \\
\hline nkt & tauk & kast & alamali \\
\hline voor & nggadi, ngadi & kat & mèo \\
\hline & & katjang & fufuè $(\mathrm{P})$ \\
\hline & J. & katoen & abas \\
\hline & & kauwen & ale \\
\hline & hei & keel & nggala botek \\
\hline jagen & sompu, sumpu & kennen & lelak (F) \\
\hline jager & manasumpu & kerk & nggalei \\
\hline jenever & ala fulak & kern (pit) & děek \\
\hline jeugdig & kanaanak & ketel & kètè \\
\hline jeuken & makètè & ketting & namosina \\
\hline & kanaanak & keuken & dapu \\
\hline nge dochter & ana fẽo mulik & kieken (kuiken) & manu-ana \\
\hline
\end{tabular}


kiekendief ( $\mathbf{z}$.

$$
\text { roofvogel) }
$$

kiezen

kikvorsch

kim

kin

kind

kip

kippenhok

kist

klagen

klap

klauw

kleed

klei

kleinkind

kleur

klimmen

klok

knie

knijpen

knoeien

knots

koe

koek

kok

kokospalm

komen

kompas

koning

koopen

koorts

kop

koper

kort

kost (spijs)

kostbaar

koud

kraai

kraal (voor vee) lalāe; okak krabbe, kreeft mpŏe he; P: nik

krabben si ; kisu

krekel tokondiik

kreng bana manamatek

krijgen (bekomen nala $(\mathrm{k})(\mathrm{P})$ 3 ps. enk)

krokodil băis, beis

krop nutuk

kruik kan

kuip pāso

kuit (van 't been) biti-boak

kunnen bolih (Mal.)

kurk tatanak

kus

iiduk

kust tasi-tataik

kwaad (onz.) tamanasa

kwaadaardig hăda manggalāuk

kwartgulden kŏal

kwijtschelden hampu holu eik

kwikzilver lilo fula òk

$\mathbf{L}$.

laag (niet hoog) kèkěuk

laat (niet vroeg) lědo (of fai) seli

lachen hika

ladder hĕda-huk

lade (v. e. kast) tadak

laf manabik; tèkèteik

lafaard bi-àò

lam bii-ana

lamp dèdědek

lampeglas nggěla dèdědek

land daè

langzaam kŏe-kŏe; fafā

lans tè ; donggi

lantaarn bānuk

lap tai sāik

last (vracht) fufuak

lasteren -kamuti 